\title{
Mejora del rango dinámico en la digitalización de documentos desde una perspectiva patrimonial: evaluación de métodos de alto rango dinámico (HDR) basados en exposiciones múltiples
}

\author{
Jesús Robledano Arillo*
}

Resumen: Uno de los principales problemas de calidad en la digitalización de documentos, especialmente de carácter gráfico, es la falta de rango dinámico en los dispositivos de captura. Una posible vía de trabajo para evitarlo es la aplicación de técnicas de alto rango dinámico (HDR) basadas en la fusión de múltiples capturas tomadas a diferentes exposiciones. Si se demuestra la idoneidad de estas técnicas en el contexto del patrimonio documental, podrían obtenerse capturas digitales de gran calidad con el empleo de equipamiento de menor coste y fácilmente asequible para instituciones con pocos recursos económicos. En este trabajo se realiza una aproximación teórica y experimental al concepto y métodos de evaluación de la calidad en la digitalización de documentos, la incidencia en la calidad del rango dinámico, y la viabilidad del uso de técnicas HDR en la digitalización de documentos con valor patrimonial.

Palabras clave: digitalización de documentos, fotografía, rango dinámico, alto rango dinámico (HDR), calidad, evaluación de calidad, patrimonio cultural.

\section{Dynamic range improvement in document digitization from a cultural heritage perspective: assessment of high dynamic range (HDR) methods based on multiple exposures}

Abstract: One of the main quality problems in document digitization, especially with graphic documents, is the low dynamic range of the capture devices. A possible way to avoid this problem is to apply high dynamic range (HDR) techniques based on multiple exposures. If these techniques prove to be suitable for the digitization of documents in the context of cultural heritage, it should be possible to obtain high quality digital captures while employing lower cost equipment, affordable enough for institutions with limited resources. In this paper we offer a theoretical and experimental approach to the concept and methods involved in the quality assessment of document digitization, the impact of dynamic range on image quality, and the viability of HDR techniques in the context of cultural beritage.

Keywords: document digitization, photography, dynamic range, high dynamic range (HDR), quality, quality assessment, cultural heritage.

* Departamento de Biblioteconomía y Documentación. Universidad Carlos III de Madrid. Correo-e: jroble@bib.uc3m.es.

Recibido: 09-11-2010; $2 .^{\mathrm{a}}$ version: 21-02-2011; aceptado: 24-02-2011. 


\section{Introducción}

Este artículo presenta, de forma sintética, el contenido del informe de investigación realizado tras el trabajo que aquí divulgamos, por lo que recomendamos el acceso a este informe a los lectores interesados en una descripción en mayor profundidad de los conceptos técnicos, metodología, aplicaciones y resultados ${ }^{1}$. El objeto de estudio son las técnicas de mejora del rango dinámico en las capturas digitales de documentos que se caracterizan por tener un elevado margen de densidades.

En digitalización de documentos, el margen de densidades es una variable que representa el rango de intensidades de luz — valores de radiancia- que se reflejan o transmiten desde las superficies a digitalizar. El rango dinámico del dispositivo de captura es un parámetro físico que representa la capacidad del dispositivo para poder registrar correctamente ese rango de intensidades de luz en una imagen digital. El registro correcto de márgenes de densidades altos en una imagen digital requiere el empleo de dispositivos de digitalización que cuenten con un alto rango dinámico; pero los dispositivos de captura digital con rangos dinámicos muy altos tienen un elevado coste, desbordando en muchas ocasiones la capacidad adquisitiva de instituciones que deben hacer frente a la digitalización de determinados tipos de documentos que requerirían este tipo de herramientas, como son los documentos fotográficos u obras de arte. En caso de no poder disponer de ellas, se hace preciso acudir al empleo de técnicas de mejora del rango dinámico como alternativa. Estas técnicas introducen métodos de captura y procesamiento digital que permiten extender el rango dinámico del dispositivo, de forma que se puedan obtener unos niveles de calidad en las imágenes digitales de los documentos similares a los que se obtendrían con los dispositivos de mayor coste. Por ello, creemos necesario dar a conocer las técnicas de mejora de rango dinámico entre los profesionales de la custodia y difusión del patrimonio documental y artístico, así como proponer pautas para su aplicación que estén amparadas en resultados de investigación rigurosos, de tal manera que muchas de las instituciones que actualmente están digitalizando fondos patrimoniales puedan beneficiarse.

Dentro de las técnicas de mejora del rango dinámico, una vía interesante de trabajo para el campo de la digitalización de patrimonio documental son aquellas que podemos englobar dentro de lo que se suele denominar como Alto Rango Dinámico o, de forma abreviada, como HDR (High Dynamic Range). Estas técnicas se basan en la fusión en una única imagen digital de varias capturas tomadas con diferentes valores de exposición. Mediante HDR se hace posible incrementar el rango dinámico en dispositivos de captura que permiten variar el nivel de ex-

${ }^{1}$ El informe puede ser accedido en el Archivo Abierto de la Universidad Carlos III de Madrid. URI: http://e-archivo.uc3m.es/handle/10016/9515. Todos los ficheros de imagen digital aplicados en el estudio pueden ser accedidos en la siguiente URL: http://rayuela.uc3m.es/ jroble/HDR/imagenes.htm. 
posición óptica — la cantidad de luz que incide sobre el sensor- durante la toma de la imagen. A lo largo de este estudio, vamos a denominar de forma abreviada como HDR a las imágenes obtenidas por este procedimiento y LDR (Low Dynamic Range - Bajo Rango Dinámico) a las imágenes obtenidas mediante una única exposición aplicando procedimientos convencionales de captura y proceso no HDR.

Las técnicas de HDR aplicadas a la captura y registro de imágenes cuyos márgenes de intensidades de luz desbordan la capacidad de los equipos convencionales se vienen empleando, cada vez más en los últimos años, en fotografía digital, tanto en el campo amateur como profesional; también han sido objeto de amplia atención por parte de la comunidad científica. Podemos encontrar descritas técnicas HDR con esta finalidad desde los comienzos de la tecnología de la imagen digital, con una alta producción de trabajos científicos desde mediados de la década de 1990 (Burt y Kolczynski, 1993; Debevec y Malik, 1997; Mann y Picard, 1995); aunque este tipo de intentos, en lo que respecta a procedimientos de captura automáticos, se iniciaron hacia mediados del siglo XIX, pocos años después de la invención y difusión de la fotografía físico-química (McCann, 2008). Nos encontramos ya en nuestros días con una tecnología HDR aplicada a la imagen digital lo suficientemente madura y con varios productos comerciales o de uso libre de gran calidad. Sin embargo, no hemos detectado planteamientos sistemáticos para su utilización en el campo de la digitalización de patrimonio documental, ni siquiera para la mejora de la captura digital de documentos que debido a sus características gráficas intrínsecas no se capturan correctamente con dispositivos convencionales o de coste asequible.

La digitalización del patrimonio documental debe regirse por unos requisitos que garanticen la máxima fidelidad en el registro de información gráfica, por ello, el uso de cualquier técnica debe ser minuciosamente estudiada para garantizar el cumplimiento de aquellos. La finalidad del trabajo que aquí presentamos es tratar de determinar la viabilidad de las técnicas HDR ante casos de documentos que presentan amplios márgenes de densidades y, en consecuencia, para los que es difícil o muy costoso encontrar dispositivos que permitan conseguir capturas de calidad sin emplear este tipo de técnicas. Hemos validado su idoneidad empleando conjuntamente parámetros de medida y métricas objetivas junto a evaluación visual subjetiva. A través de nuestro trabajo también proponemos una metodología que puede ser apropiada para investigar la validez de las técnicas HDR en el campo de la digitalización del patrimonio documental y utilizamos esta metodología para la evaluación de una aplicación HDR concreta.

Debido a la amplia variedad de productos para generar imágenes HDR en el mercado, hemos seleccionado uno de los más utilizados, por estar integrado en el conocido y extendido editor profesional de imágenes Adobe Photoshop CS; en concreto la función Combinar para HDR de la versión CS4. Vamos a abordar el empleo de HDR con documentos cuyos márgenes de densidades no son muy altos, no más de 2,6 D. No obstante, estos márgenes de densidades permiten cubrir buena parte del patrimonio documental y artístico custodiado en archivos, bibliotecas y museos; especialmente aquellos documentos de soporte opaco que 
se capturan mediante luz reflejada: fotografías, documentos manuscritos e impresos y obras de arte sobre papel, pergamino, tela y soportes similares.

En este estudio nos movemos en el contexto de la calidad de las digitalizaciones de documentos. En los últimos años asistimos a una amplia producción científica en el campo del control de calidad de dispositivos de captura digitales, que de forma gradual está incorporándose en el contexto de la digitalización de patrimonio documental (Frey y Reilly, 2006; Berns y Frey, 2006; Williams, 2002; Williams, 2003; Kenney y Rieger, 2000; Stelmach, 2010). Un ejemplo de aplicación real en este campo lo tenemos en las especificaciones técnicas de NARA (U.S. National Archives and Records Administration) (Puglia y otros, 2004) o en el GAP Analysis (Still Image Working Group, 2010), en los que se han llegado incluso a identificar aquellos aspectos tecnológicos relacionados con el control de calidad en las digitalizaciones de patrimonio documental que deben ser mejorados y recibir más atención por parte de la comunidad científica. Otro trabajo relevante al respecto lo tenemos en el campo de la normalización de métodos y cartas de control, donde es especialmente activo el Grupo ISO/TC42. De este grupo han emanado importantes estándares (ISO, 2000; ISO 2003a; ISO, 2003b; ISO, 2004a; ISO, 2004b; ISO, 2009a; ISO, 2009b; Loebich y Wueller, 2001; Williams, 2003). En este sentido, es importante la iniciativa para la creación de una carta unificada estandarizada a partir de la cual se puedan evaluar todos los parámetros físicos relevantes para medir la calidad de un dispositivo de captura: la Universal Test Target (Wueller y otros, 2009). La investigación en métodos de evaluación de rendimiento en equipamiento de captura digital de imágenes se ha visto incrementada significativamente en los últimos años desde los campos de la Ciencia y Tecnología de la Imagen (Wueller, 2006; Loebich y otros, 2007). Todo este trabajo ha dado sus frutos también como implementación y comercialización de paquetes de aplicaciones software y cartas de control normalizadas para poder realizar de forma relativamente sencilla la evaluación, tales como IE Analyzer de Image Engineering ${ }^{2}$, Golden Thread de Image Science Associates ${ }^{3}$ e Imatest ${ }^{4}$.

\section{El problema de un rango dinámico insuficiente para la calidad de la digitalización}

El rango dinámico se calcula restando las densidades óptica máxima y mínima que el dispositivo de captura puede registrar con calidad. La densidad óptica alude a la capacidad de una superficie para retener parte de la luz que incide sobre ella, y se expresa como:

Densidad óptica $=-\log _{10}$ del factor de transmisión o de reflexión

${ }^{2}$ Sitio Web en http://www.image-engineering.de/index.php?option=com_content\&view=article \&id=137\&Itemid=50.

3 Sitio Web en http://www.imagescienceassociates.com/

${ }^{4}$ Sitio Web en http://www.imatest.com/. 
siendo el factor de transmisión el cociente entre el flujo luminoso que transmite un cuerpo transparente y el flujo incidente, y el factor de reflexión el cociente entre el flujo luminoso reflejado por un cuerpo opaco y el flujo incidente.

En general, el rango dinámico de un dispositivo de captura idóneo para la digitalización de la superficie de un documento debe ser igual o mayor que el rango de densidades de esa superficie. El rango o margen de densidades se calcula mediante la resta de la máxima y mínima densidad óptica de la superficie a capturar. Los problemas de calidad en las imágenes debidos a escasez de rango dinámico pueden ser realmente graves: o bien no se captura toda la información gráfica del documento, o parte de esta información queda registrada de forma defectuosa, limitándose en gran medida las posibilidades de uso posterior de las imágenes digitales.

Los principales defectos que muestran las imágenes capturadas con poco rango dinámico son la posterización y el recorte tonal de luces o sombras; ambos suelen presentarse de forma conjunta. La posterización — también denominada como artefactos de cuantización - se produce cuando un conjunto determinado de valores tonales diferenciados —intensidades de luz - adyacentes o cercanos, tomados de una escena o documento a capturar digitalmente, se intenta representar mediante un número más reducido de valores digitales en la imagen resultante de su captura; esto es, la entrada de valores tonales en el dispositivo de captura es mayor que su salida en la imagen digital. Como resultado de la posterización, las gradaciones tonales sutiles de una imagen se ven sustituidas por zonas de tono uniforme a modo de bandas o manchas de extensión variable, que se pueden hacer bien visibles al ojo humano si su incidencia es alta. La posterización no es algo que afecta sólo a capturas digitales a bajas profundidades de bits ( 8 bits o menos por canal de color); desgraciadamente, es frecuente incluso que se produzca en las capturas digitales a altas profundidades de bits, como es el caso de las imágenes de prueba realizadas para este estudio, que han sido capturadas a 16 bits por cada canal de color RGB. En este tipo de capturas la posterización se produce cuando zonas importantes de información gráfica de la imagen original se capturan con valores tonales excesivamente oscuros para el límite de rango dinámico concreto del dispositivo de captura que se está usando. El sensor del dispositivo de captura recibe de esas zonas menos luz y las registra, consiguientemente, subexpuestas y posterizadas. La posterización de las zonas tonales más oscuras se produce en los dispositivos digitales debido a la asignación lineal de bits a los diferentes rangos de intensidad de luz que se aplica durante el momento de la conversión analógica digital, a pesar de que la información luminosa decrece de forma logarítmica con la exposición. Esto provoca que un rango tonal determinado, a medida que se va llevando a las zonas de sombra durante la captura, se vaya comprimiendo con respecto a la escala lineal de asignación de bits y, consecuentemente, recibiendo menor número de bits para su descripción, y, por tanto, habiendo una menor posibilidad de que se le asignen valores tonales en la imagen digital final.

Además, al efecto de la posterización hay que sumar el recorte tonal provocado por la escasez de rango dinámico, que se produce en los tonos de sombra 
cuya escasa intensidad de luz desborda la capacidad de detección del sensor: la información gráfica correspondiente a esos tonos desaparece en el registro de la imagen quedando registrado un único valor para esas zonas. Si a estos dos problemas sumamos la mayor incidencia de ruido al aplicarse a la imagen las correcciones de gamma y de contraste necesarias para su visualización, la calidad de la captura quedará seriamente en entredicho.

Para mejorar la comprensión de los defectos que queremos medir incluimos la figura 1, que muestra la comparativa de la captura de una zona con información tonal de alta densidad de una fotografía junto con los parches más densos de la escala de parches de densidad Q13 de Kodak. La primera fila muestra la captura subexpuesta, con dos valores de exposición menos de lo que le correspondería; la segunda fila muestra lo mismo pero con una exposición normal. Los defectos aparecen señalados. En la exposición normal hay posterización, pero su incidencia es menor que en la subexposición, debido a que el sensor del dispositivo de captura recibe más luz de las zonas de alta densidad.

\section{FIGURA 1}

\section{Comparativa de incidencia de problemas de rango dinámico en función de} diferentes valores de exposición

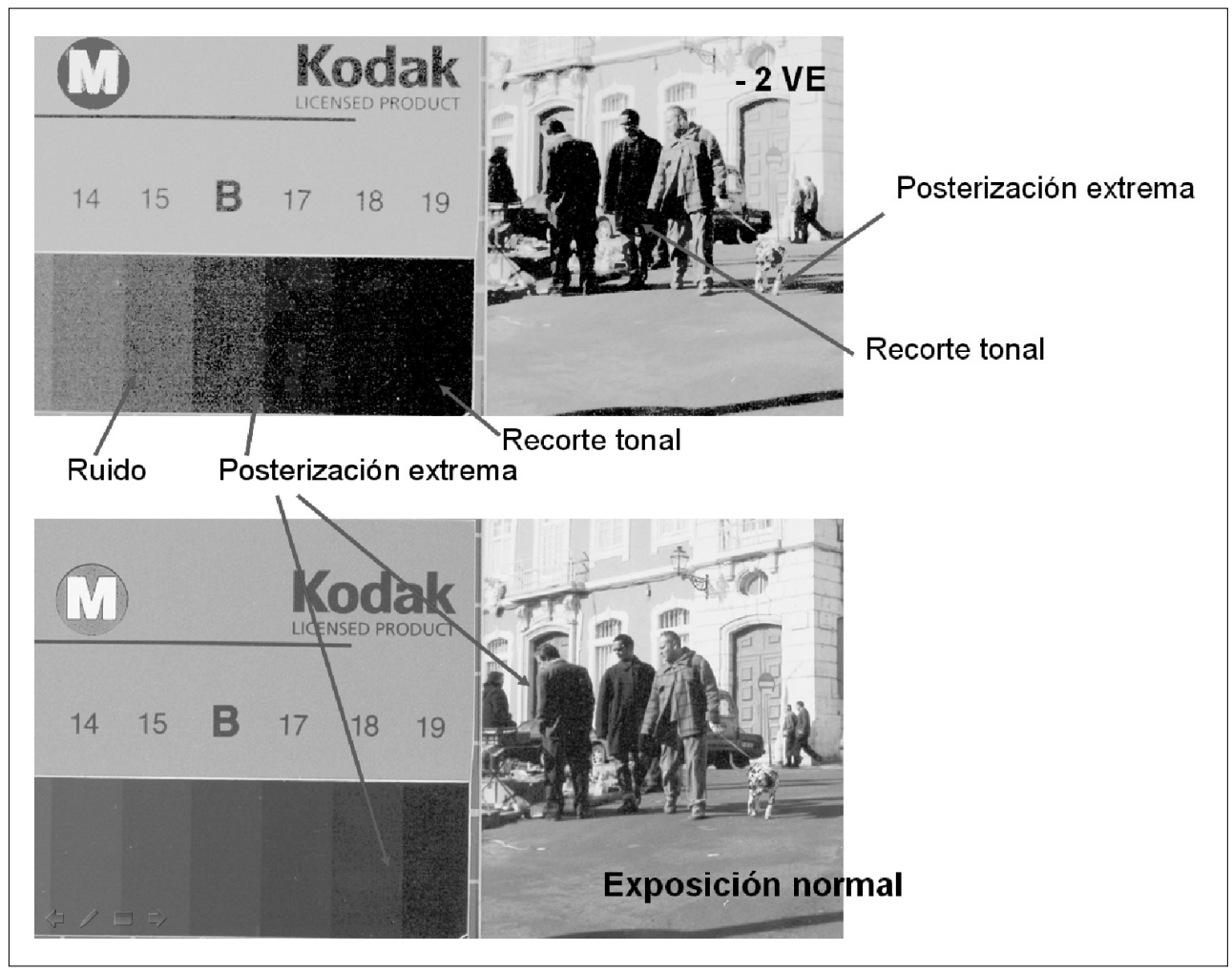




\section{La aportación de las técnicas HDR}

El HDR se basa en realizar diferentes imágenes de la escena o documento a digitalizar. Cada imagen se realiza con un valor de exposición distinto, de forma que se asegure que cualquier nivel de intensidad de luz de la captura quede registrado con calidad suficiente al menos en alguna de ellas. A partir de este conjunto de imágenes se calcula una nueva imagen con un rango dinámico muy amplio. La posterización y recorte de información en las zonas más oscuras se evita aprovechando su mejor descripción, gracias a una mayor asignación de bits, en las imágenes que son sobreexpuestas en la captura.

Para el almacenamiento del fichero máster HDR, que es producto de la fusión de las múltiples exposiciones, se usan formatos específicos que permiten registrar en una única imagen HDR toda la información capturada en las diferentes tomas. Su profundidad de bits puede llegar a ser muy alta, como en el caso del TIFF de coma flotante, hasta 96 bits. Las imágenes representadas en estos ficheros no son visibles directamente en monitores convencionales debido a su limitada razón de contraste y gama de colores, por lo que es necesario emplear lo que se denomina como métodos de compresión de luminancias o de mapeo tonal (tone mapping) y de mapeo de gama (gamut mapping) (Mantiuk y otros, 2005). Mediante el mapeo tonal las imágenes pasan a una versión LDR para su visualización e impresión, con una profundidad de bits de 16 u 8 bits por canal. Es durante el proceso de mapeo cuando se selecciona del total de tonos de luz y color captados en el rango dinámico aquellos que van a ser incluidos en el margen de densidades y espacio de color del dispositivo de visualización o impresión.

\section{Metodología}

\subsection{Primera fase. Captura digital y procesado HDR y LDR}

Hemos utilizado una cámara fotográfica digital réflex de formato pequeño de gama media-alta, en concreto la Canon EOS 5D. Se trata de un modelo de cámara de coste medio, profesional, con una relación calidad/precio equilibrada y asequible, típica de centros o instituciones con pocos recursos. Las capturas se han realizado en ficheros con formato RAW nativo de la cámara, que posteriormente han sido procesados en un editor Adobe Photoshop CS4, mediante el plugin Adobe Camera RAW.

Se han digitalizado dos grupos de documentos (denominados, respectivamente, grupo 1 y grupo 2). De cada grupo se han hecho dos capturas (denominadas, respectivamente, imagen 1 e imagen 2). Las capturas del primer grupo contienen:

- Carta Q13 y carta Q14, ambas de Kodak, para la evaluación del rendimiento en el registro tonal mediante los parámetros físicos de rango dinámico, gamma, contraste y ruido. 
- Carta Colorchecker mini de X-rite, para la evaluación del rendimiento en el registro del color.

- Dos cartas para prueba MTF, para la evaluación del rendimiento en el registro del detalle espacial de forma objetiva mediante la aplicación de una función MTF.

- Carta PM-189, construida de acuerdo a las recomendaciones de la norma ANSI (ANSI/AIIM, 1988), para la evaluación del rendimiento en el registro del detalle espacial de forma subjetiva, mediante evaluación visual.

Las capturas del segundo grupo contienen elementos de control y testigos con unas características gráficas comunes a documentos típicos de patrimonio documental gráfico fotográfico:

- Carta de acuerdo al estándar IT.8 reflectante de Kodak.

- Carta Colorchecker mini.

- Cartas Q13 y Q14 de Kodak.

- Fotografías en blanco y negro modernas, con un margen de densidades típico, ligeramente superior a $2 \mathrm{D}$.

- Fotografía en monocromo histórica, de principios del siglo xx, iluminada a mano con anilinas.

- Fotografías en color cromógeno contemporáneas.

- Testigo con un amplio margen de densidades, consistente en una diapositiva en color capturada como si fuera material reflectante. Este testigo permite medir el comportamiento del HDR en zonas de densidad muy altas pero con mucho detalle gráfico espacial.

Los procedimientos fotográficos seleccionados para las muestras son habituales en muchos fondos fotográficos patrimoniales. Se ha pretendido incorporar en las capturas de prueba elementos que permitan evaluar visualmente y objetivamente los diferentes parámetros de rendimiento que se han incluido en el estudio. La duplicación de capturas que se hace en cada uno de los grupos corresponde a la necesidad de cotejar que el rendimiento de la técnica HDR sea constante captura a captura, y, por consiguiente, los resultados consistentes.

Por cada una de las imágenes de cada grupo se ha generado una versión en HDR, producto de la fusión de ocho tomas realizadas con diferentes valores de exposición. Las exposiciones se han separado entre sí por un Valor de Exposición (un paso de diafragma). Estas capturas se ajustan bien al ratio de contraste de las imágenes de prueba con mayor margen de densidades, que es de aproximadamente 400:1. El formato de los ficheros HDR es TIFF de coma flotante de 32 bits por canal de color. A partir de cada uno de los cuatro ficheros HDR máster, se ha generado una versión LDR con mapeo tonal a 16 bits por canal de color RGB. A estas versiones las denominamos Mapeadas HDR. La función de las versiones mapeadas es poder evaluar los parámetros físicos de forma objetiva y subjetiva. El mapeo tonal se ha hecho desde el mismo programa Adobe Photoshop CS4, utili- 
zando el operador de mapeo Exposición y gamma, con los parámetros gamma 1 y exposición 0,50. Estos valores generan una curva de contraste que arroja valores adecuados para la generación y aplicación de un perfil de color ICC sobre la base de la carta Colorcheckr. Se ha elegido este operador de mapeo porque deriva en una mayor fidelidad entre el documento físico digitalizado y la representación visual obtenible a partir de esa imagen, al aplicar sólo procesamientos lineales.

Se ha capturado, además, una versión LDR convencional, de una única toma fotográfica, de cada uno de los cuatro grupos de captura. Estas capturas se han realizado con un valor de exposición típico para la digitalización de documentos: para densidad de gris del 18\% de reflectancia. El formato de estos nuevos másteres LDR es TIFF a 48 bits. El objetivo los másteres LDR es cotejar el rendimiento en calidad de las capturas LDR convencionales de una única toma con el rendimiento en calidad de sus correspondientes imágenes LDR derivadas por procedimiento de mapeo tonal desde las versiones HDR generadas con múltiples tomas. De esta forma podremos evaluar la ganancia en calidad de la técnica HDR frente a la captura no HDR y la incidencia que aquella puede tener en cuanto a fidelidad en el registro del detalle gráfico de los documentos.

Se ha aplicado gestión de color tanto a las imágenes LDR mapeadas desde HDR como a las imágenes capturadas directamente como LDR, generándose un perfil ICC de color a partir de la carta Colorchecker incluida en las imágenes. La gestión de color se ampara bajo el supuesto de un comportamiento uniforme del dispositivo y procesado de captura en todas las sesiones de captura en las que se usa un mismo perfil ICC, por lo que no es recomendable aplicar de forma conjunta gestión de color y técnicas de mapeo tonal basadas en procesamientos no lineales. Como hemos comentado más arriba, la técnica de mapeo tonal aplicada se basa en ajustes lineales, por lo que podríamos considerar que tenemos consistencia al menos dentro de cada imagen. Bajo esta hipótesis, hemos hecho las pruebas de error en la codificación de color generando un perfil ICC personalizado para cada una de las imágenes.

\subsection{Segunda fase. Aplicación de parámetros físicos y subjetivos visuales}

Para la evaluación comparada — en cuanto al rendimiento en el registro de la información gráfica de los documentos originales- de las imágenes LDR derivadas de HDR frente a sus correspondientes capturas LDR convencionales de una única toma, hemos empleado parámetros físicos que pueden medirse de forma objetiva y automatizada y, también, de forma subjetiva a través de cotejo visual por un experto humano. Los parámetros físicos han sido:

\section{Rango dinámico}

Se han venido utilizando múltiples métodos para medir el rango dinámico, con mayor o menor objetividad (Wueller, 2002); la propia ISO ha publicado un 
estándar específico para escáneres (ISO, 2004b). En este estudio hemos usado el método aplicado por el programa Imatest, que ofrece una función suficientemente flexible para el cálculo del rango dinámico: mide el rango dinámico en valores de exposición (EV) y con diferentes niveles de calidad en función de la proporción de ruido.

\section{Ruido}

La norma ISO 157391 define el ruido como variaciones indeseadas en la respuesta de un sistema de imagen (ISO, 2003b). En este trabajo no nos interesa tanto medir el ruido del dispositivo empleado, sino determinar cómo varía la incidencia del ruido en el procesado HDR frente al procesado convencional LDR. Una explicación detallada de las métricas para la medición del ruido lo tenemos en el propio estándar ISO (ISO, 2003b) y en otros trabajos que lo desarrollan (Kleinmann y Wueller, 2007). Hemos utilizado una métrica de ruido que presenta una buena correlación con la percepción visual humana de este problema: la medida de ruido para el canal de luminancia como porcentaje de la diferencia de valores de píxel, entre el parche más oscuro y el más claro, correspondiente a un margen de densidades de 1,5 D (Koren, 2010b). La medida se basa en los parches de densidad de la carta Q13 y arroja un promedio del ruido total de la imagen.

\section{Espectro de ruido}

La gráfica del espectro de ruido que hemos empleado nos muestra el ruido en función del valor de frecuencia espacial. Estos datos evidencian el efecto que determinados procesamientos de la imagen digital, como la posible aplicación de filtros de paso bajo — antialiasing y antirruido - en la cámara digital o durante el procesado RAW, pueden tener en la captación del detalle espacial fino. Estos procesados pueden causar la pérdida de detalle espacial fino en áreas uniformes de la imagen o que presenten detalle caracterizado por altas frecuencias espaciales y poco contraste. Creemos útil usar este parámetro para comprobar si el procesado HDR aplicado en las imágenes de prueba implica algún procedimiento que puede derivar en la eliminación de patrones gráficos semejantes al ruido, y que pueden estar presentes en zonas de imágenes fotográficas con grano o en zonas que muestren determinadas texturas de grano fino. La eliminación del ruido implicaría la pérdida o reducción de este tipo de información tonal y de detalle espacial, que evidentemente, no sería adecuada en una digitalización patrimonial.

\section{Capacidad resolutiva}

El término capacidad resolutiva se utiliza para referir la potencia de un sistema óptico o de registro de imágenes resolviendo detalle espacial de pequeño 
tamaño. Para medir la capacidad resolutiva hemos empleado la métrica MTF (Modulation Transfer Function). Esta métrica ha tenido y tiene un amplio uso en Ingeniería Óptica, Fotografía e Ingeniería de Imagen para la evaluación del rendimiento de ópticas y dispositivos de registro y reproducción de imágenes. Además, ha sido estandarizada por ISO, tanto para la evaluación de escáneres como de cámaras fotográficas digitales (ISO, 2000; ISO, 2003; ISO, 2004) y está ampliamente documentada en múltiples trabajos teóricos y experimentales sobre evaluación de calidad en imágenes fotográficas digitales. MTF es una función que expresa cómo se transfiere el contraste existente en el límite de dos áreas colindantes, de muy alta y muy baja densidad respectivamente. Hemos aplicado la MTF al escaneado de una carta de tipo ISO 12233 Slanted-edge Spatial Frequency.

Antes de aplicar la MTF, hemos calculado los valores óptimos y límite para el rendimiento en la función MTF en un contexto de captura con un sensor digital basado en la discretización de la imagen en puntos, como es el sensor CMOS de la cámara empleada para las pruebas. Para ello, hemos aplicado la siguiente ecuación, donde intentamos incorporar la incertidumbre derivada de la diferente probabilidad de alineación o no alineación del detalle espacial de pequeño tamaño en las celdillas fotosensibles del sensor, donde se proyecta la imagen captada por el sistema óptico de la cámara digital, en función de la resolución espacial de captura que se emplee:

$$
\mathrm{C}=(\mathrm{R} / 50,8) / \mathrm{F}
$$

donde $\mathrm{C}$ indica los ciclos por milímetro - los pares de línea en una carta de resolución de pares de línea por milímetro o ciclos de densidad en una carta de resolución con patrón sinusoidal - que deben quedar bien resueltos a diferentes valores de resolución espacial de captura en el dispositivo digital de registro de imágenes; $\mathrm{R}$ es una variable que expresa la resolución espacial de captura en píxeles por pulgada que se está evaluando; 50,8 es una constante cuya inclusión permite distribuir de forma proporcional los píxeles capturados por cada pulgada lineal entre cada una de las líneas que se toma como referencia de tamaño de detalle fino en una carta de resolución de pares de líneas por milímetro —dividiendo el valor de resolución en píxeles por pulgada por esa constante podemos conocer los píxeles que corresponden a cada línea de la carta-; F es un factor de calidad que permite resolver la incertidumbre en la alineación del detalle espacial fino contra las celdillas fotosensibles (píxeles) del sensor, incorporando a la medida tres situaciones de calidad: Baja, Buena y Excelente. El factor Bajo equivale a la frecuencia de Nyquist, esto es, al valor de resolución espacial que se está aplicando, el sensor sólo dispone de un píxel para cada línea de la carta. La probabilidad de que ese píxel coincida de forma exacta con una línea de la carta es muy baja, por lo que se estima que hay una alta probabilidad de mala calidad en el registro del detalle fino que podría ser bien registrado a ese valor de resolución espacial. El factor Bueno equivale a 
que el sensor utiliza 1,5 píxeles para cada línea de la carta, lo que incrementa considerablemente la probabilidad de alineación correcta del detalle de una línea con un píxel; Excelente equivale a que el sensor emplea 2 píxeles para cada línea de la carta, con lo que la probabilidad de coincidencia de al menos un píxel completo en cada línea de la carta es del 100\%, asegurándose el registro correcto de todas las líneas de la carta, salvo en casos de un penoso rendimiento del sistema óptico del dispositivo de captura o un enfoque erróneo durante ésta.

Aplicando la ecuación anterior, hemos derivado los valores de rendimiento para la prueba MTF a 246,55 píxeles por pulgada, el valor de resolución espacial de captura de las imágenes de prueba con carta para MTF, que mostramos en la tabla I. Como podemos observar, hemos correlacionado en la tabla los valores de MTF con la escala de calidades en que se basan los factores de calidad en la ecuación anterior.

TABLA I

Valores de rendimiento para la prueba MTF a 246,55 píxeles por pulgada

\begin{tabular}{c|c|c|c}
\hline & $\begin{array}{c}\text { Baja calidad } \\
\text { (MTF 20\%) }\end{array}$ & $\begin{array}{c}\text { Buena calidad } \\
\text { (MTF 50\%) }\end{array}$ & $\begin{array}{c}\text { Calidad excelente } \\
\text { (MTF 60\%-70\%) }\end{array}$ \\
\hline Pares de líneas mm. & 4,85 & 3,24 & 2,43 \\
\hline Líneas por pulgada & 246 & 164 & 123 \\
\hline
\end{tabular}

Para la evaluación visual de la capacidad resolutiva hemos usado la carta PM-189.

\section{Aberración cromática lateral}

Se trata de un problema propio de los defectos de los sistemas ópticos que se acoplan a los dispositivos de captura, pero que pueden ser magnificados por el procesamiento digital aplicado durante el procesado RAW y HDR. En la aberración cromática lateral las diferentes longitudes de onda que conforman el espectro de los colores de la imagen enfocan en el mismo plano, pero con desplazamientos laterales respecto del eje central. Este fenómeno se manifiesta bajo la forma de halos de color alrededor de zonas de borde y alto contraste representadas en la imagen. La métrica de la aberración cromática lateral escogida es la del área en píxeles de la aberración cromática. Lo hemos medido mediante el programa Imatest, que detecta automáticamente la aberración de la zona de alto contraste marcada y la mide. La escala de valores de referencia para la calidad en este parámetro la hemos tomado de la propuesta por el mismo programa: menos de 0,5, no significativo; entre 0,5 y 1 , menor; entre 1 y 1,5, moderado; 1,5 o superior, severo. 


\section{Error en la codificación de color}

Para la evaluación objetiva y subjetiva de rendimiento en la codificación de color, a las imágenes de la carta Colorcheckr representadas en las versiones HDR y LDR, una vez convertidas al espacio Adobe RGB, les hemos aplicado diversas métricas estandarizadas para la medida de la diferencia o distancia entre colores a partir de su representación codificada, encuadrables en lo que se denomina Color Encoding Error. En concreto, hemos manejado las métricas Delta E y Delta $\mathrm{C}$ sobre el espacio de color perceptual e independiente CIELAB. Los datos que arrojan estas métricas han sido utilizados, en concreto, para cotejar de forma comparada la consistencia de los métodos de procesamiento HDR y LDR, con la finalidad de poder determinar si el HDR permite conseguir una consistencia y proximidad de color en una reproducción similar al LDR, mediante la intermediación de la tecnología de gestión de color, o no.

La evaluación subjetiva se ha incluido, a modo de refuerzo de las pruebas objetivas, para determinar la corrección de la apariencia de las imágenes reproducidas en cuanto a contraste y color, así como la apreciación visual de artefactos que distorsionan la representación de los elementos gráficos de los documentos en la imagen digital, tales como posterización, recortes tonales, pérdida de detalle espacial fino y ruido.

Los parámetros físicos sólo han sido aplicados al primer grupo de dos imágenes, el que contiene cartas para la medición objetiva de los parámetros físicos. El segundo grupo contiene muestras para la evaluación subjetiva visual, que han sido complementadas con carta para evaluación objetiva o subjetiva de rango dinámico y contraste.

\section{Resultados y discusión}

\subsection{Capacidad resolutiva y aberración cromática lateral}

\subsubsection{Resultados de las medidas objetivas de parámetros}

Las gráficas que mostramos a continuación son las ofrecidas por el propio programa Imatest a partir de los datos derivados tras aplicar las funciones indicadas sobre dos regiones de la digitalización resultante de la carta: una región vertical y otra horizontal. En la figura 2 representamos datos precisos de MTF en las regiones medidas, en másteres HDR y LDR, mediante los gráficos resumen generados por el propio Imatest.

En la figura 3 hemos reflejado datos más precisos de aberración cromática en ambas regiones, en másteres HDR y LDR.

En el máster HDR se detecta una cierta pérdida de resolución: el valor para MTF50\% ponderado es inferior al que debería: 2,75 ciclos por milímetro (Cy/mm) frente a los 3,24 esperados; el valor para MTF20\% también es más bajo que el esperado. La diferencia con el valor esperado a MTF50\% no es muy alta, aproxi- 
FIGURA 2

\section{Datos MTF}

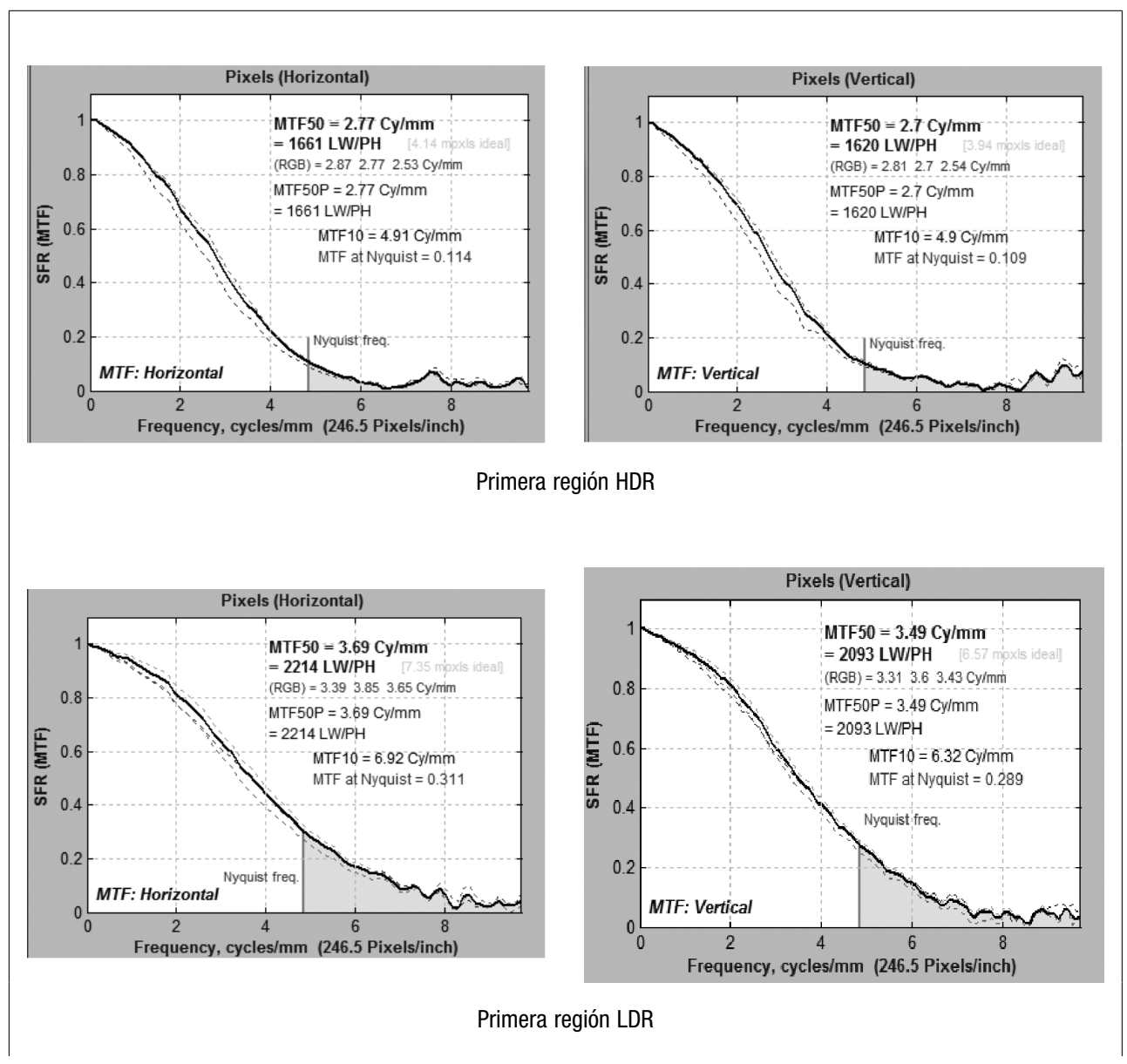

madamente $0,5 \mathrm{Cy} / \mathrm{mm}$. A frecuencia Nyquist (un píxel por línea) el valor MTF es ligeramente superior a $10 \%$ en ambos sentidos, horizontal y vertical, salvo en la medida vertical de la segunda región. Esto indica que la capacidad resolutiva límite del HDR se ha mantenido, pudiendo registrar de forma visible detalles de un grosor igual al del píxel a la resolución de captura empleada para la imagen, por lo que no hay merma en la representación del detalle espacial más pequeño representable por la cámara digital y objetivo empleado a esa resolución espacial de captura. En el caso de la aberración cromática en HDR, nos movemos justo por debajo del valor 0,5 , por lo que su afectación no es significativa. En el máster LDR no se detecta ninguna pérdida de resolución: el valor para MTF50\% ponderado coincide prácticamente con el valor esperado $(3,33 \mathrm{Cy} / \mathrm{mm}$ frente a 


\section{FIGURA 2 (continuación)}
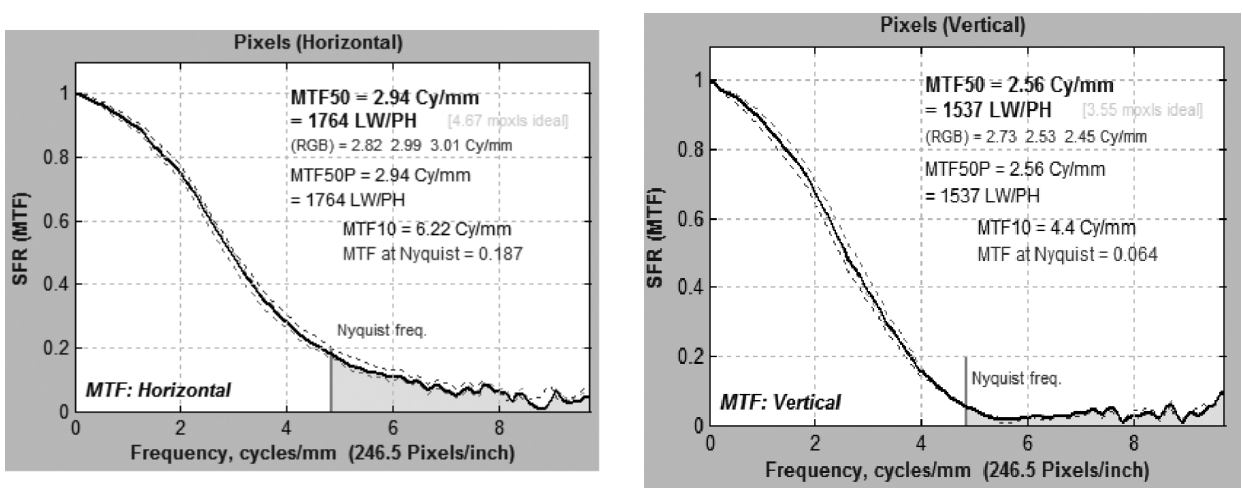

Segunda región HDR
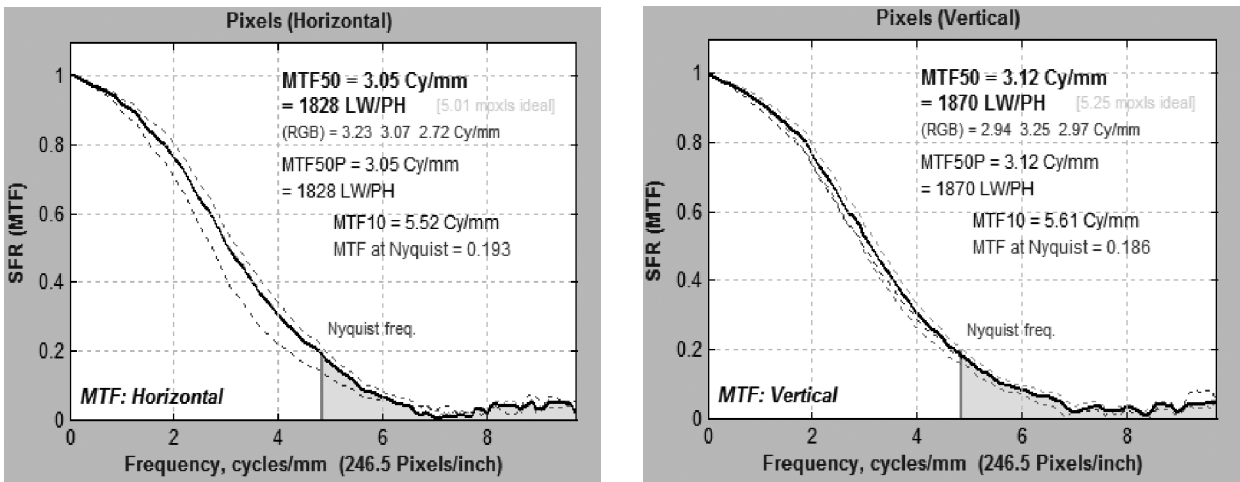

Segunda región LDR

3,24 Cy/mm esperados). En la primera región medida, en la versión LDR, se dan valores por encima del valor esperado, lo que puede estar indicando un mínimo aumento artificial de nitidez en el procesado de la cámara y RAW. Este aumento de nitidez se ha perdido durante el procesado HDR, al incorporar éste un mínimo suavizado de contraste en altas y bajas frecuencias espaciales, algo que ha sido detectado también en las pruebas visuales complementarias que hemos incluido en el estudio. En el caso de la aberración cromática, en la versión LDR nos movemos también por debajo del 0,5 , por lo que su afectación no es tampoco significativa, salvo en la segunda zona en el lado horizontal. El LDR arroja también valores mejores de afectación de la aberración cromática lateral, aunque nos situamos en ambos másteres en valores no significativos a esta resolución espacial. 
FIGURA 3

\section{Datos sobre aberración cromática}
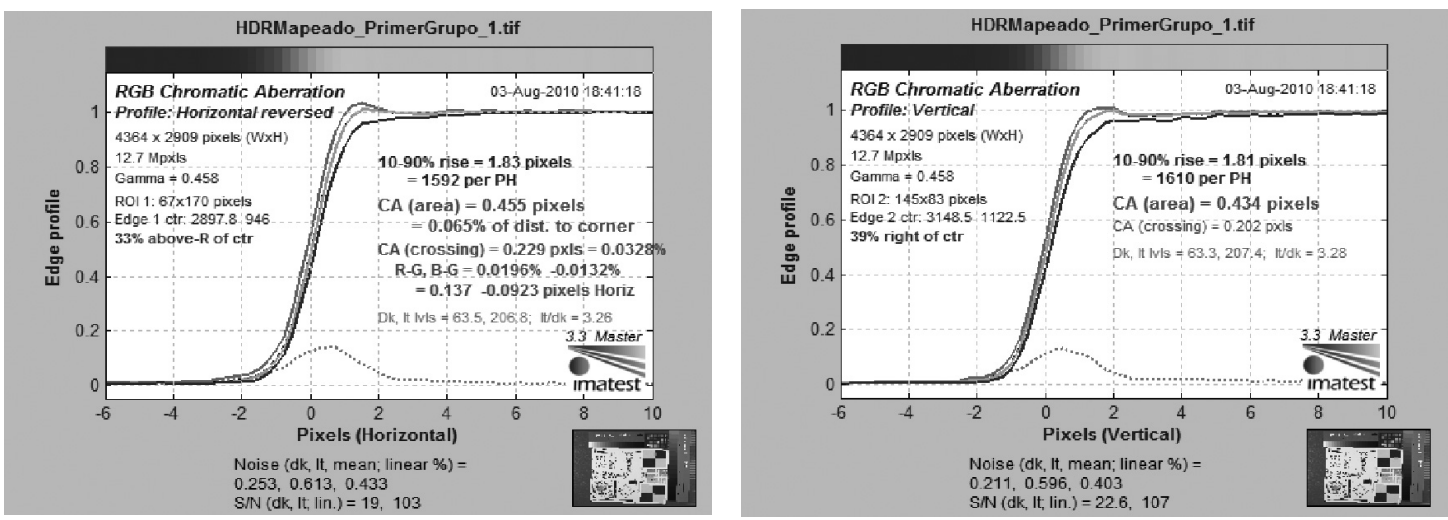

Primera región HDR
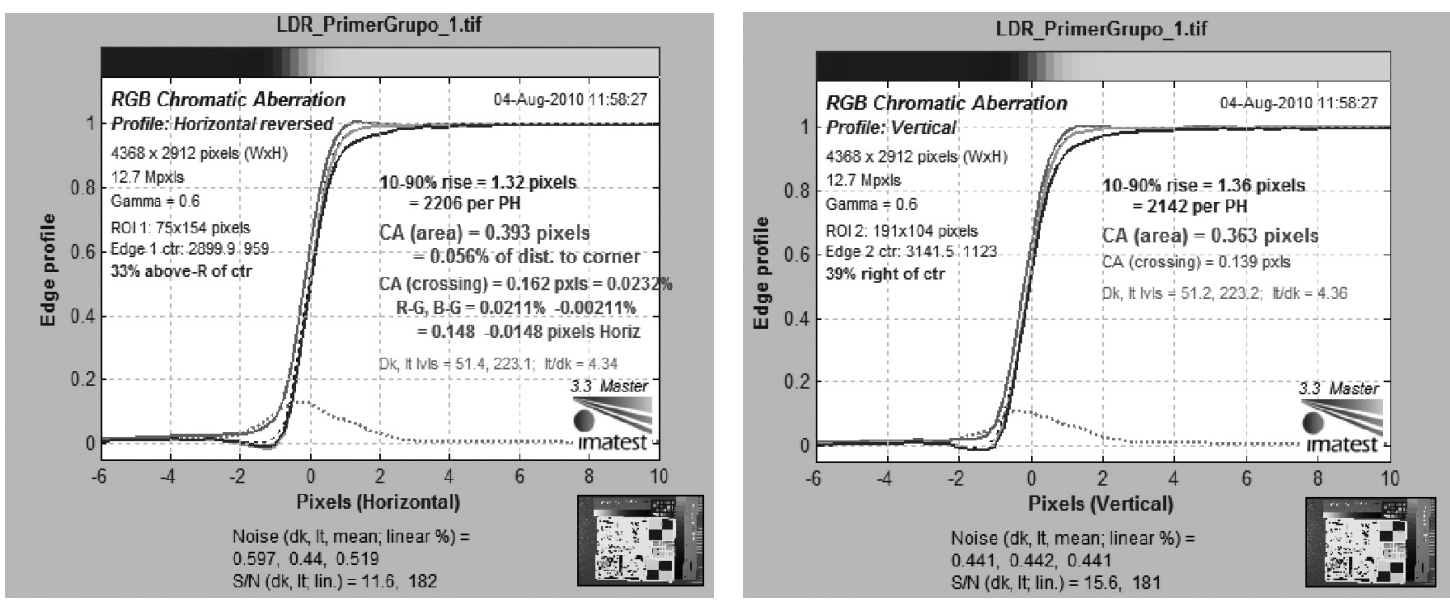

Primera región LDR

\subsubsection{Resultados de la evaluación subjetiva de parámetros de capacidad resolutiva}

La evaluación subjetiva se ha realizado a ambos grupos de imágenes de prueba. Su objetivo no es sólo contrastar los resultados de los métodos objetivos de medición, sino también valorar la consistencia en el rendimiento del procesamiento HDR de una imagen a otra imagen. Se han evaluado dos zonas de la carta PM-189: el texto impreso a diferentes tamaños y los patrones axiales de pares de líneas por milímetro. La selección de estas dos zonas se debe a que incluyen dos elementos importantes de información de los documentos: letras y 


\section{FIGURA 3 (continuación)}
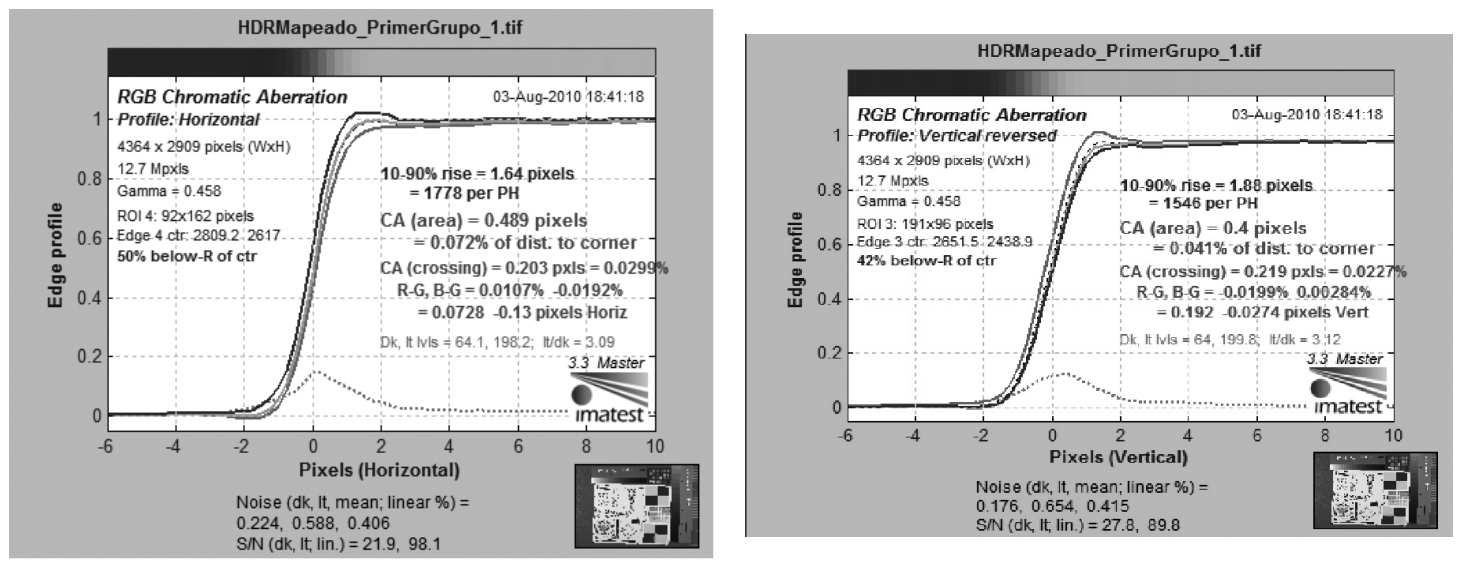

Segunda región HDR
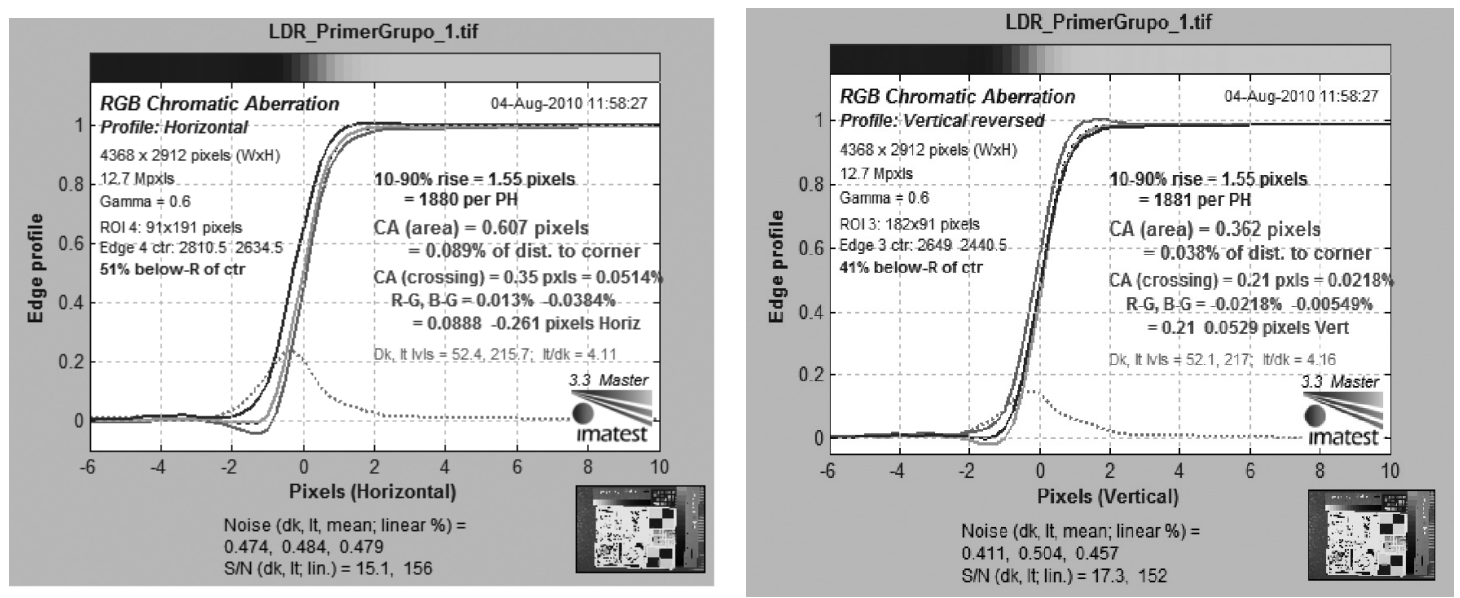

Segunda región LDR

trazos finos que pueden estar presentes en una amplia gama de medios: manuscritos, dibujos, grabados, fotografías, pinturas, textos de imprenta, etc. Es preciso ser muy cautelosos con la evaluación visual de la capacidad resolutiva mediante patrones gráficos de líneas, debido a que por debajo de la resolución de Nyquist (un píxel por línea) surgen muarés que pueden engañar fácilmente al observador, haciéndole creer que hay líneas bien resueltas donde no las hay. Los muarés se presentan como patrones gráficos de interferencia, y son resultado de la ruptura del patrón a evaluar ante una resolución espacial insuficiente. Tanto las pruebas en HDR como en LDR arrojan unos buenos resultados en la comparativa visual de textos y pares de líneas. No notamos visualmente la merma de MTF que evi- 
denciaban las pruebas objetivas. Los textos son legibles en HDR y LDR. El HDR se muestra también consistente en cuanto a capacidad resolutiva en las diferentes capturas realizadas.

A continuación, hemos evaluado detalles de las fotografías del grupo 2 que muestran zonas de altas frecuencias espaciales. Hemos elegido zonas de detalle donde la afectación por falta de rango dinámico sea mínima, ya que aquí no estamos evaluando problemas tonales, sino de capacidad resolutiva. En las zonas evaluadas de las fotografías, salvo algo de posterización y ruido en LDR, no hay diferencia alguna en la captación del detalle espacial fino relevante entre HDR y LDR; pero en las densidades más altas sí hemos detectado mayor ruido y posterización, que alteran no sólo la reproducción tonal y de color, sino también la representación del detalle fino. En zonas de detalle espacial con densidades más altas, el detalle en LDR se ve distorsionado, con una incidencia directamente proporcional a la de afectación de los problemas de rango dinámico. Esta apreciación parece evidenciar que el uso de dispositivos de rango dinámico inferior al margen de densidades de los documentos a escanear puede provocar, incluso aunque la capacidad resolutiva sea alta, distorsión y pérdida de detalle espacial de pequeño tamaño, especialmente en zonas de altas frecuencias espaciales.

\subsection{Representación tonal}

\subsubsection{Evaluación objetiva}

Mostramos en la figura 4 datos precisos sobre el rendimiento tonal en los parámetros ruido, espectro de ruido y rango dinámico, en másteres HDR y LDR.

La afectación de ruido es menor en HDR, $Y=0,23$ contra $Y=0,43$. Esto se reproduce en todos los canales de color. Pero hemos de considerar que en HDR no se han contado los dos últimos pasos que son los más ruidosos. Si nos atenemos a la comparativa de los parches anteriores a estos dos no captados en HDR, el nivel de ruido es menor siempre en HDR, por debajo de 0,5 siempre. Los tres últimos pasos de densidad del LDR evidencia una cantidad de ruido muy alta, inaceptable, por lo que no podemos considerar estos tres pasos dentro del rango dinámico de la captura si aplicamos unos criterios patrimoniales rigurosos. Por ello, el rango dinámico en la versión LDR habría que reducirlo a 1,6 D, siendo incluso cuestionable la aceptación del paso de densidad anterior al máximo aceptado. En HDR todos los parches detectados están muy por debajo del 0,5 de ruido. También hemos detectado una pérdida ligera de contraste en HDR frente a LDR, lo que puede propiciar una menor acentuación del ruido en las zonas de sombra. Esto lo detectamos mediante el gráfico Density Response, que representa la OECF. La OECF (Función de Conversión Opto-Electrónica) correlaciona la densidad óptica de cada parche de la carta Q13 con los valores promediados de luminosidad de los píxeles que describen esos parches, tras los ajustes de contraste propios del procesado de los ficheros RAW y del HDR. Si nos fija- 
mos en este gráfico, en la versión LDR podemos observar un aumento de contraste mediante una ligera curva en S. En HDR se ha suavizado el contraste durante el proceso de mapeo tonal y durante la fusión de imágenes tomadas a diferentes valores de exposición.

Las representaciones gráficas del espectro de ruido evidencian que la caída de la gráfica es más brusca en el caso de HDR. No obstante, en ambas gráficas se muestra una caída del ruido a medida que decrece la frecuencia espacial, lo que parece reflejar que se ha incluido procesamiento antirruido y antialiasing durante el procesado RAW o, previamente, en los circuitos de la cámara. Esta caída debería manifestarse como un cierto suavizado de contraste en zonas con texturas finas de bajo contraste, que tendría que ser, de acuerdo a la mayor brusquedad de la caída de la gráfica, mayor en HDR. Este hecho ha sido contrastado visualmente durante la evaluación subjetiva, donde hemos apreciado zonas con este tipo de texturas que, aunque no se pierden, sí bajan su contraste y se hacen menos aparentes al ojo.

\subsubsection{Evaluación subjetiva}

Se han evaluado aspectos como la diferenciación de los pasos de densidad de la carta Q13, la presencia visible de ruido, posterización y recortes tonales. En todas las capturas se diferencian perfectamente los 20 parches de densidad de la carta Q13. Aunque el contraste es mayor en las LDR, debido a la pérdida de rango dinámico, a la peor identificación y representación de los tres últimos parches más densos, y a una curva gamma menor. Hemos de destacar, asimismo, la alta consistencia en los resultados de unas capturas a otras de las mismas cartas de prueba.

La evaluación visual de los tres últimos parches de densidad ampliados nos ha llevado a la conclusión de que no se observa posterización ni ruido visible en ninguna de las versiones HDR, habiendo una gran consistencia en los resultados de las dos capturas. En cuanto a las dos versiones LDR, hemos observado posterización y ruido muy visibles en ambas capturas, con distorsión de detalle en los tres últimos parches de densidad de la carta Q13. Hemos profundizado más en este aspecto, evaluando detalles escogidos de zonas más densas en las fotografías representadas en el segundo grupo de capturas, tanto en color como en blanco y negro. Los resultados de esta evaluación demuestran que tanto en los detalles de color como en blanco y negro, podemos observar una alta incidencia de posterización y ruido en LDR, con gran distorsión y pérdida del detalle en las densidades más altas. Estos problemas no los apreciamos en HDR. Estas pruebas reflejan una pérdida de información tonal muy visible en las imágenes LDR, que puede ser crítica para la digitalización de fotografía, tanto en color como en blanco y negro, y sobre base opaca y traslúcida; pues estas densidades son muy comunes en esta clase de materiales.

De cara al posible uso de la cámara digital empleada, mediante técnicas LDR o HDR, para la digitalización de materiales con mayores márgenes de densidad 


\section{FIGURA 4}

\section{Rendimiento tonal}

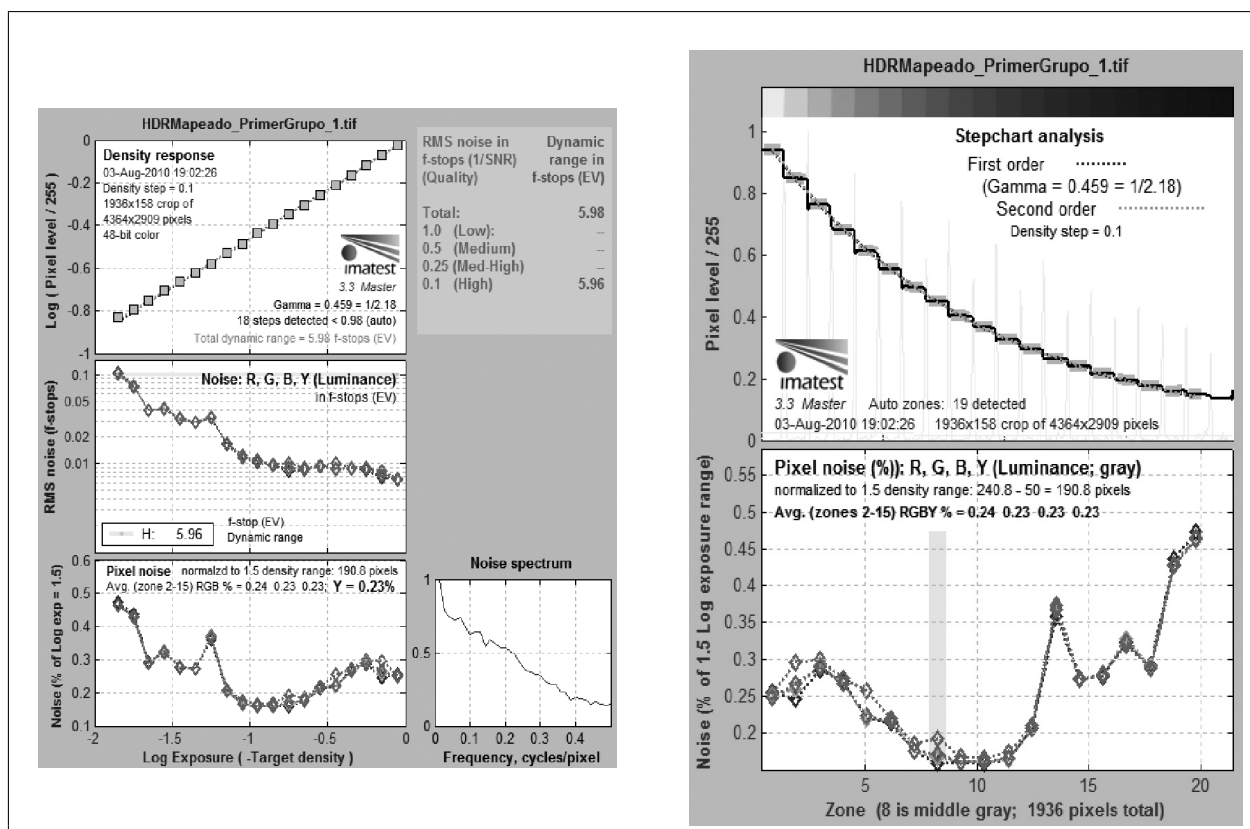

HDR. Rango dinámico, ruido y espectro de ruido/Pasos de densidad detectados y ruido
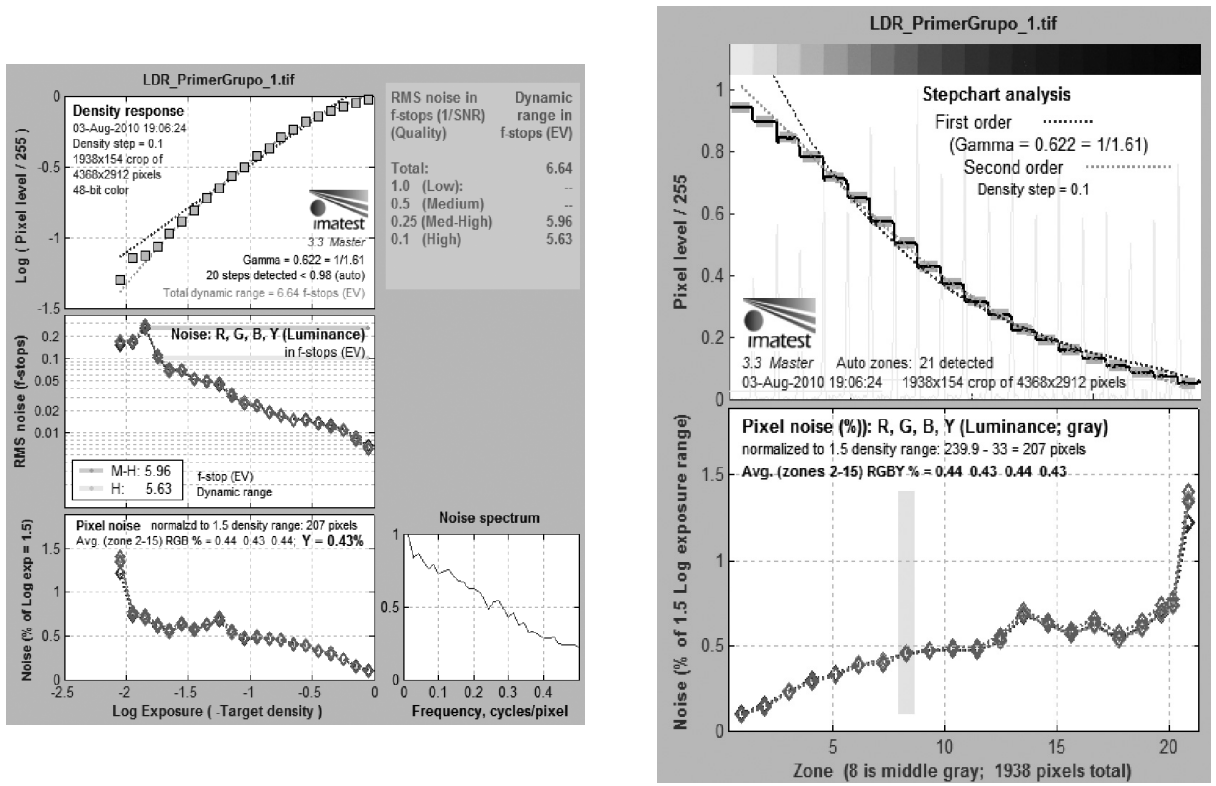

LDR. Rango dinámico, ruido y espectro de ruido/Pasos de densidad detectados y ruido 
que los representados en las cartas Q13 y Q14, nos interesa también evaluar el comportamiento de ambas técnicas en zonas con densidades superiores a 1,95 D. Para ello, hemos capturado detalles de zonas de densidad en torno a 2,6 D, que mostramos en la figura 5.

\section{FIGURA 5}

Detalles en zonas de densidad en torno a 2,6 D

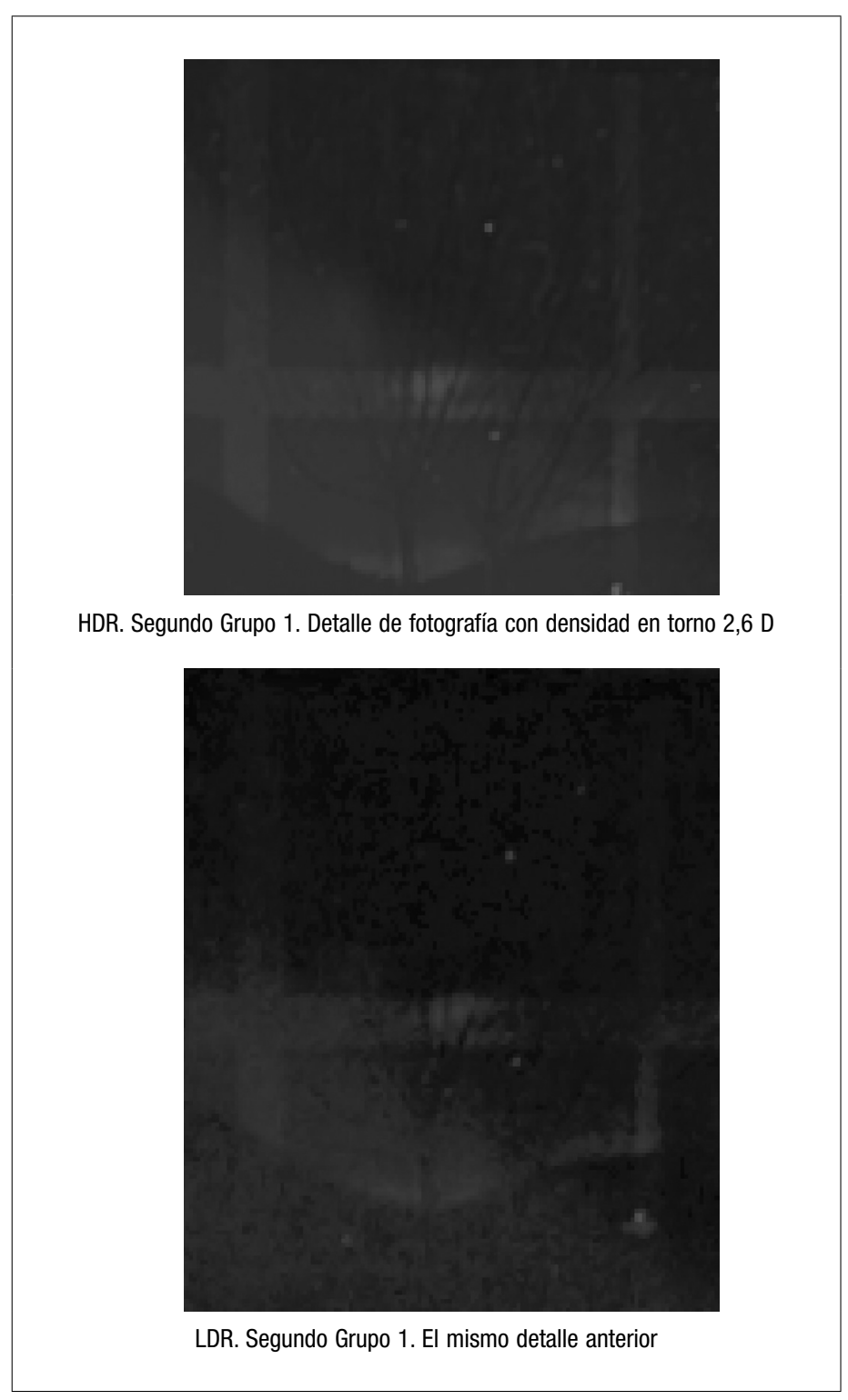


El resultado es muy evidente: LDR no capta detalle a esas densidades, y presenta mucho ruido, posterización y recorte tonal. También se demuestra que el rango dinámico de la versión HDR supera en mucho el margen de densidades de la carta de densidades Q13 analizada. Parece que con las técnicas HDR se puede mejorar muchísimo el rendimiento tonal de un dispositivo con escaso rango dinámico y que HDR no implica merma en la representación del detalle, al menos hasta estos valores de densidad máxima que estamos manejando en el estudio y con la técnica de mapeo tonal empleada.

\subsection{Color}

\subsubsection{Evaluación objetiva}

Presentamos en la figura 6 los datos obtenidos en las pruebas colorimétricas mediante los gráficos aportados por el programa Imatest que hemos empleado para las medidas de color. Los gráficos muestran la distancia de color en el plano de crominancia $a^{*} b^{*}$ del espacio CIELAB (Koren, 2010a). También se ha calculado la media (Mean) de todos los errores de color, el valor máximo (max) y el valor medio de saturación (Mean camera chroma). Estos datos aparecen en la parte de arriba a la derecha de cada gráfico. Valores medios de saturación por encima del $100 \%$ indican un aumento de la saturación general de la imagen digital con respecto a la saturación ideal de los colores de la carta de prueba. Un exceso de saturación podría significar la pérdida de detalles en zonas de color altamente saturados en el documento, por lo que es interesante también valorar este aspecto.

En cuanto a saturación, HDR y LDR arrojan resultados similares, con un aumento muy ligero de la saturación que es muy poco perceptible. En cuanto a precisión medida sobre la carta Colorcheckr, las diferencias en los valores medios y máximos entre ambas versiones son tan mínimas - siempre inferiores a la unidad- que podemos despreciarlas, tanto en métrica Delta E como Delta C. Los gráficos muestran un patrón de error de color prácticamente idéntico entre ambas versiones. No podemos considerar que LDR presente mayor precisión en color que HDR, ni viceversa.

\subsubsection{Evaluación subjetiva}

El cotejo visual original/reproducción digital se ha realizado en una cabina de visualización normalizada, con un monitor marca EIZO, calibrado, caracterizado y ajustado en cuanto a temperatura de color e intensidad de punto blanco de forma coordinada con las condiciones de visualización de la cabina. Para ello hemos seguido estándares y recomendaciones profesionales para cotejo visual de imágenes, especialmente el estándar ISO 3664:2009.

La apariencia visual subjetiva es prácticamente idéntica en reproducción tonal y contraste entre HDR y LDR. La apariencia de color en ambas muestras, HDR y LDR, es muy similar, salvo algunas diferencias en color, que se perciben como co- 
lores que no tienen exactamente el mismo grado de saturación o tono. En las versiones LDR la diferencia en contraste y saturación es mayor en la apreciación visual, con el agravante de que la imagen LDR no puede ser igualada en cuanto a apariencia con el original manteniendo una calidad visual aceptable; el bajo rango dinámico de la cámara digital empleada lo impide. En cambio, la igualación de apariencia se ha solucionado satisfactoriamente en la versión HDR mapeada tonalmente.

\section{Conclusiones}

Es importante concienciar a los profesionales que tienen responsabilidad sobre la digitalización de patrimonio documental, especialmente patrimonio fotográfico y pictórico, de la necesidad de contar con dispositivos de captura que permitan el rango dinámico necesario para capturar el margen de densidades de los documentos. Tanto el rango dinámico del dispositivo, con los ajustes y parámetros de captura a aplicar, como el margen de densidades de los documentos deben ser medidos antes de la captura, debiendo ser el primero al menos igual o, preferiblemente, superior al segundo. En su defecto, se deberá seleccionar una técnica HDR adecuada para aquellos documentos en los que se estime que el rango dinámico del dispositivo es insuficiente, mediante pruebas que evalúen el rendimiento en el registro de información tonal, cromática y detalle espacial.

En las pruebas realizadas en este estudio, no hemos detectado diferencia en la capacidad resolutiva de las imágenes HDR frente a las LDR con el método de procesamiento HDR empleado. En ambos tipos de imágenes hemos podido registrar con el mismo nivel de calidad aquellos detalles espaciales de tamaño pequeño o grande que son registrables por el dispositivo de captura digital empleado con la configuración de captura elegida.

El HDR mejora muy significativamente el rango dinámico de dispositivos de captura con escaso rango dinámico, como son las cámaras réflex digitales; posibilita que se puedan capturar documentos con amplios márgenes de densidades, más allá de la propia capacidad del dispositivo, permitiendo el registro correcto de información tonal, espacial y cromática sin defectos graves de calidad, tales como ruido alto, posterización y recorte tonal en zonas de luces o de sombras.

No se han detectado diferencias significativas entre HDR y LDR en cuanto a la calidad de registro de color, empleando métricas estandarizadas para la medida de error de color; tampoco en cuanto a la percepción subjetiva de proximidad original/imagen visualizada en un monitor con condiciones de entorno de visualización controladas. En cuanto a la viabilidad de uso de perfiles ICC, tampoco se ha detectado ningún problema, pero es recomendable, a la espera de estudios que aborden con más profundidad este aspecto, que los perfiles se realicen sobre una carta de color, apta para su creación, digitalizada en el mismo acto de captura del documento, pues el procesado HDR puede incluir ajustes no lineales que hacen perder la consistencia en la reproducción de la carta entre escaneado y escaneado o dentro de zonas distintas en cuanto a contenido gráfico de la misma imagen. 
FIGURA 6

Gráficos comparativos de datos de distancia de color en las digitalizaciones
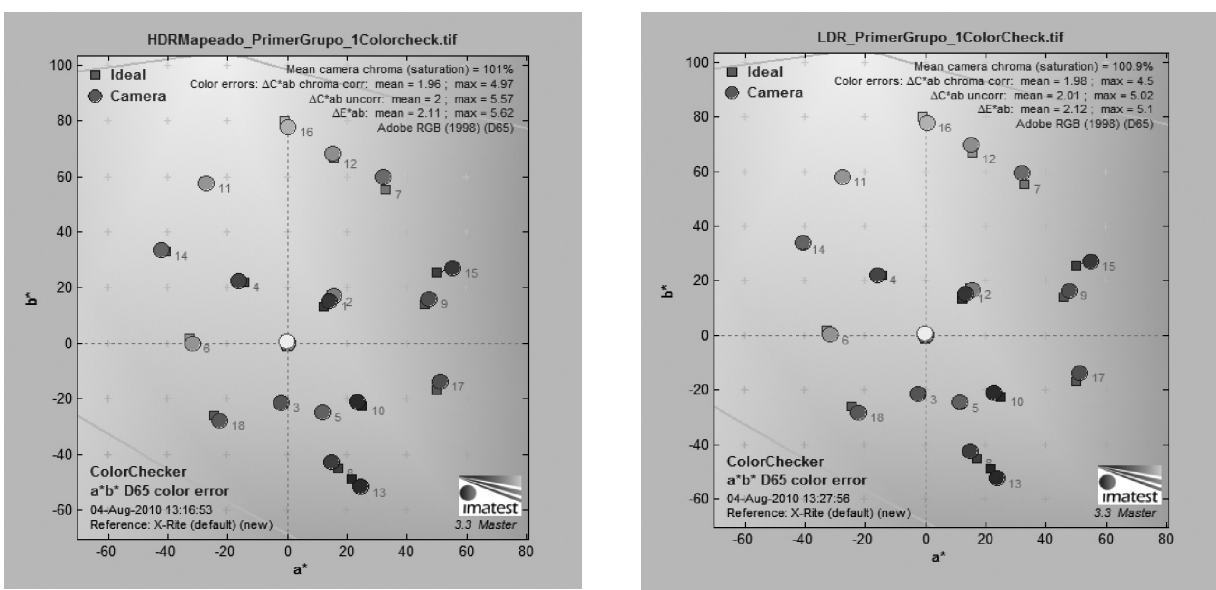

Primera región HDR
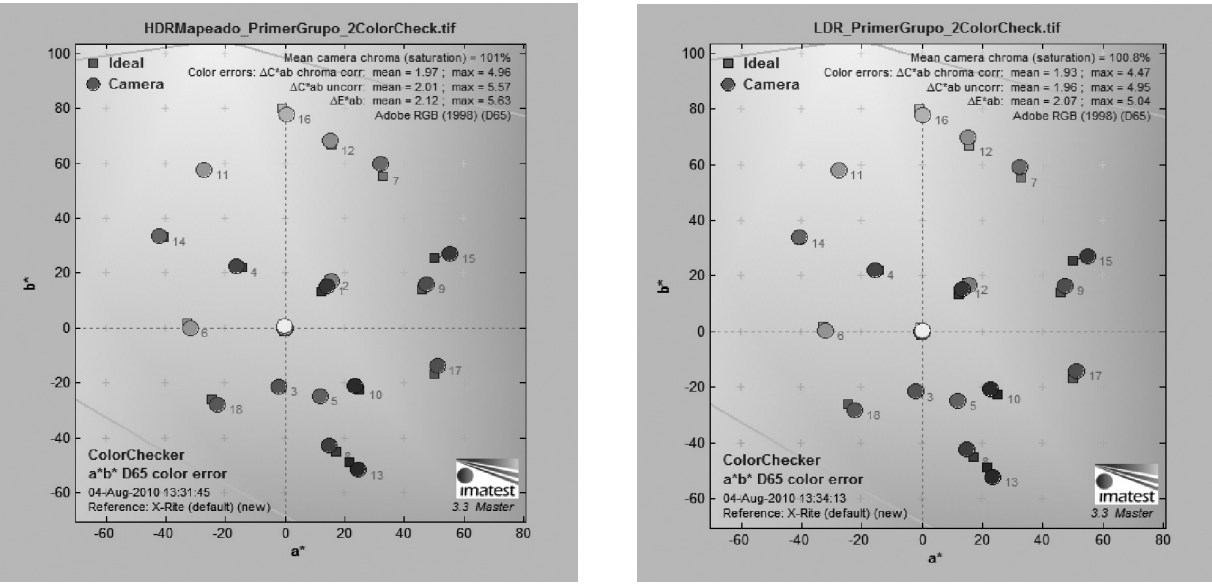

Primera región LDR

Creemos que es necesaria una investigación más pormenorizada al respecto, analizando la respuesta de la gestión de color ante colores presentes en los documentos a escanear que estén alejados, en cuanto a luminosidad o cromaticidad, de los colores normalizados de la carta empleada para hacer el perfil de color.

Las pruebas realizadas evidencian que hay consistencia en el procesado HDR - con el método captura multiexposición, fusión y mapeo que hemos aplicadode imagen a imagen. Por consiguiente, se podría conseguir consistencia en la 


\section{FIGURA 6 (continuación)}
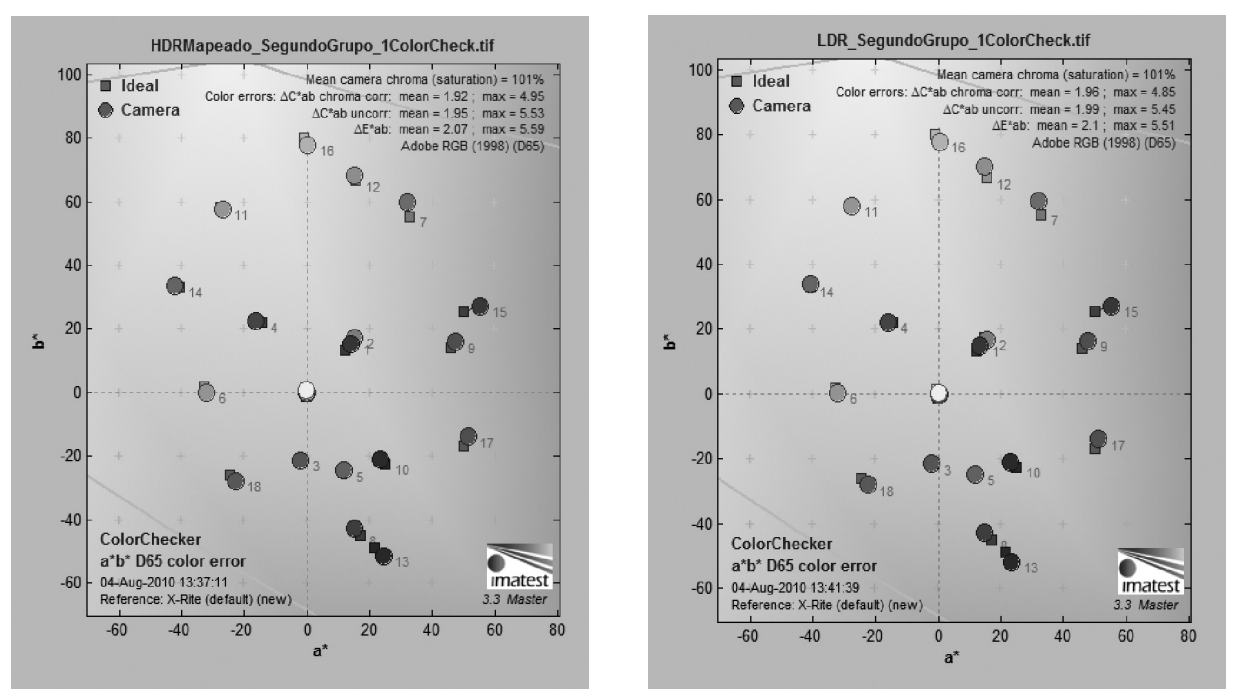

Segunda región HDR
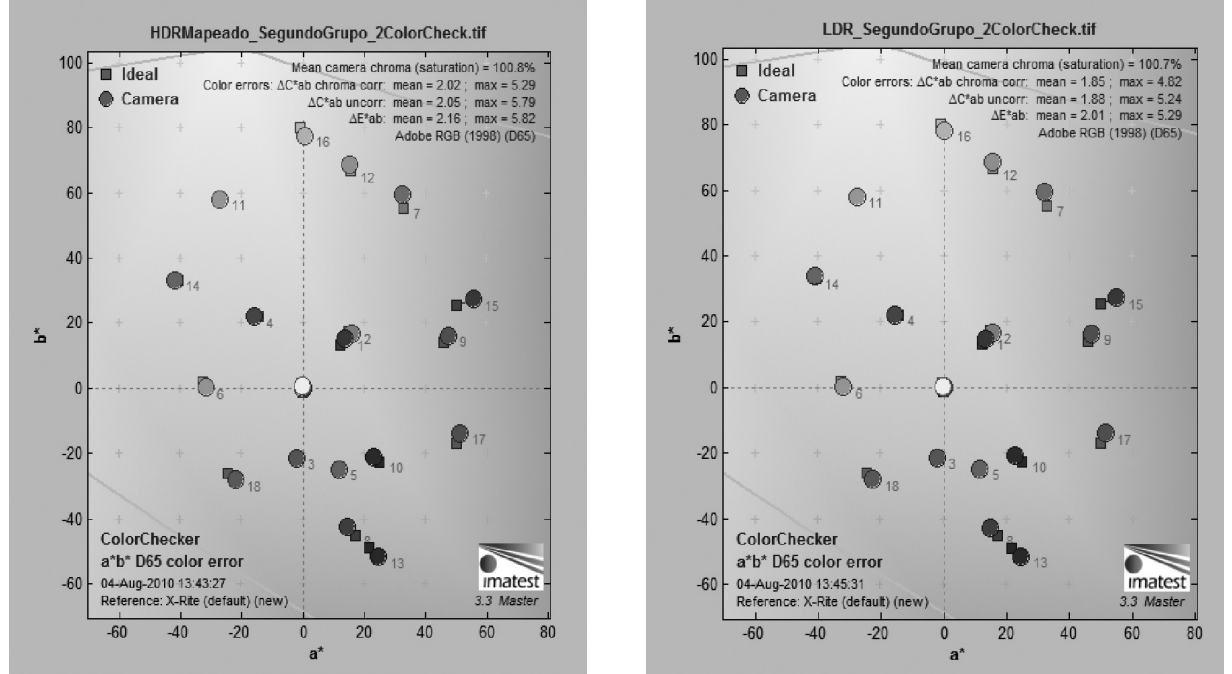

Segunda región LDR

calidad de resultados para la digitalización de un fondo completo. No obstante, convendría hacer más pruebas con una muestra más amplia, que contemplase diferentes tipos de medios y documentos. 
Gracias al uso de técnicas HDR, con una cámara fotográfica digital de coste medio-bajo, hemos podido obtener, perfectamente reproducido, un rango dinámico en torno a 2,6 D, que equivale a 8,6 diafragmas (f/stop); no ofreciendo esta cámara, con técnicas de digitalización LDR, más de 1,7 D o 5,6 diafragmas con calidad suficiente. Por ello, creemos que la técnica de HDR presentada y analizada en este estudio es utilizable en la digitalización de patrimonio documental en situaciones en las que no se cuente con suficientes recursos para el escaneado de documentos con amplios márgenes de densidad, pero con una serie de matizaciones.

En primer lugar, hay que considerar que los resultados de este estudio no son extensibles más allá del margen de densidades de los documentos y cartas de prueba, con una densidad máxima de 2,6 D. Estos márgenes de densidades no son problemáticos para la técnica de mapeo tonal que hemos empleado, menos agresiva y apta para posibilitar una interpretación facsímil de un documento fotográfico que otras; pero con márgenes de densidades mayores, esta técnica podría no dar los mismos resultados, debiéndose optar por otras más agresivas con la información gráfica del documento. Para densidades y márgenes de densidades mayores a los incluidos en este estudio recomendamos hacer pruebas adicionales, donde se demuestre la idoneidad de éste u otros procedimientos de HDR.

En segundo lugar, hay que contar con los problemas de eficiencia añadidos al HDR: el mayor consumo de tiempo para la captura y procesado de la imagen, el tener que manejar y gestionar múltiples ficheros de gran tamaño, la necesidad de un control minucioso en el momento de generar el mapeo —que exigiría un control visual de todas las imágenes-, la necesidad de involucrar más recursos en las digitalizaciones, y un control de calidad más exhaustivo. Este problema de eficacia puede hacer más aconsejable acudir a equipamientos de alto coste que ofrezcan un rango dinámico suficiente cuando los lotes de documentos a digitalizar sean muy voluminosos.

\section{Bibliografía}

ANSI/AIIM MS44-1988 (1988): Recommended Practice for Quality Control of Image Scanners.

Artmanna, U., y Wueller, D. (2008): Noise Reduction vs. Spatial Resolution. Proceedings of SPIE, vol. 6817, 68170A.

Berns, R. S., y Frey, F. S. (2005): Direct Digital Capture of Cultural Heritage-Benchmarking American Museum Practices and Defining Future Needs. Rochester; Rochester Institute of Technology, Munsell Color Science Laboratory [en línea]. Disponible en http:// www.cis.rit.edu/museumSurvey/documents/Benchmark_Final_Report_Web.pdf [fecha de consulta 5/08/2010].

Burt, P. J., y Kolczynski, R. J. (1993): Enhanced image capture through fusion. Proceedings of the ICCV, 173-182.

Debevec, P. E., y Malik, J. (1997): Recovering high dynamic range radiance maps from photographs. Proceedings of ACM SIGGRAPH, 369-378. 
Frey, F., y Reilly, J. M. (2006): Digital Imaging for photographic collections: foundations for technical standards. (2. ${ }^{a}$ ed.) Rochester; Image Permanence Institute [en línea]. Disponible en http://www.imagepermanenceinstitute.org/shtml_sub/digibook.pdf [fecha de consulta 25/08/2010].

ISO 12233:2000 (2000): Photography - Electronic still-picture cameras - Resolution measurements.

ISO 16067-1:2003 (2003a): Photography - Spatial resolution measurements of electronic scanners for photographic images - Part 1: Scanners for reflective media.

ISO 15739:2003 (2003b): Photography - Electronic still picture imaging - Noise measurements.

ISO 16067-2:2004 (2004a): Photography - Electronic scanners for photographic images Spatial resolution measurements - Part 2: Film scanners.

ISO 21550:2004 (2004b): Photography - Electronic scanners for photographic images Dynamic range measurements.

ISO 14524:2009 (2009a): Photography - Electronic still-picture cameras - Methods for measuring opto-electronic conversion functions (OECFs).

ISO 3664:2009 (2009b): Graphic technology and photography - Viewing conditions.

Kenney, A. R., y Rieger Y. O. (2000): Moving Theory into Practice: Digital Imaging for Libraries and Archives. Mountain View, CA: Research Libraries Group.

Kleinmann, J., y Wueller, D. (2007): Investigation of two methods to quantify noise in digital Images based on the perception of the human eye. Proceedings of SPIE, the International Society for Optical Engineering, vol. 6494, 64940N.1-64940N.12.

Koren, N. (2010a): Running Imatest SFR [en línea]. Disponible en http://www.imatest.com/ docs/sfr_instructions2.html [fecha de consulta 5/08/2010].

Koren, N. (2010b): Noise in photographic images [en línea]. Disponible en http://www. imatest.com/docs/noise.html [fecha de consulta 5/08/2010].

Koren, N. (2010c): Using Colorcheck [en línea]. Disponible en http://www.imatest.com/ docs/colorcheck.html [fecha de consulta 5/08/2010].

Loebich, C., y Wueller, D. (2001): Three Years of Practical Experience in Using ISO Standards for Testing Digital Cameras. Proceedings of the Image Processing, Image Quality, Image Capture Systems Conference (PICS-01), Montréal, Quebec, Canada, abril, 22-25, 2001, IS\&T 2001, 257-261.

Loebich, C.; Wueller, D.; Klingen, B., y Jaeger, A. (2007): Digital Camera Resolution Measurement Using Sinusoidal Siemens Stars. En: Martin, R. A; DiCarlo, J. M; Sampat, N. (Eds.). Digital Photography III, edited by Proceedings of SPIE-IS\&T Electronic Imaging, SPIE, vol. 6502 [en línea]. Disponible en http://www.image-engineering.de/images/ pdf/conference_papers/resolution_measurement.pdf [fecha de consulta 5/08/2010].

Mann, S., y Picard, R. (1995). Being "undigital" with digital cameras: Extending dynamic range by combining differently exposed pictures. Proceedings of ISE T, $46^{\text {th }}$ annual conference, 422-428.

Mantiuk, R.; Daly, S.; Myszkowski, K., y Seidel, H.-P. (2005): Predicting visible differences in high dynamic range images - model and its calibration. Human Vision and Electronic Imaging X, IST/SPIE's 17 th Annual Symposium on Electronic Imaging, vol. 5666, 204-214 [en línea]. Disponible en http://www.mpi-inf.mpg.de/ mantiuk/papers/mantiuk05PredVisDiff.pdf [fecha de consulta 25/08/2010]. 
McCann, J. J. (2008): Perceptual rendering of HDR in painting and photography. Preprint of 6806-30 paper in SPIE/ISET Electronic Imaging Meeting, San Jose, January, 2008 [en línea]. Disponible en http://web.me.com/mccanns/Color/Color_Reproduction_ files/08EI\%206806-30.pdf [fecha de consulta 25/08/2010].

Puglia, S.; Reed, J., y Rhodes. E. (2004): U.S. National Archives and Records Administration (NARA) - Technical Guidelines for Digitizing Archival Materials for Electronic Access: Creation of Production Master Files- Raster Images [en línea]. Disponible en http:// www.archives.gov/preservation/technical/guidelines.pdf. [fecha de consulta 26/08/2010].

Stelmach, M. (2010): Evaluating digital image performance device capability and image quality. Presentation by Michael Stelmach at an August, 2010 workshop sponsored by CENDI, FLICC and FADGI [en línea]. Disponible en http://www.digitizationguidelines. gov/stillimages/documents/Evaluating_Digital_Imaging-2010.pdf [fecha de consulta 25/08/2010].

Still Image Working Group (2010): GAP Analysis. Updated 01/12/2010 [en línea]. Disponible en http://www.digitizationguidelines.gov/stillimages/documents/Gap_Analysis. pdf [fecha de consulta 25/08/2010].

Williams, D. (2002): Image quality metrics. RLG Diginews, vol. 4 (4) [en línea]. Disponible en http://www.worldcat.org/arcviewer/1/OCC/2007/08/08/0000070511/viewer/file1806. html [fecha de consulta 24/08/2010].

Williams, D. (2003): Debunking of Specsmanship: Progress on ISO/TC42 Standards for Digital Capture Imaging Performance. ISET'S 2003 PICS Conference, 77-81 [en línea]. Disponible en http://www.i3a.org/wp-content/uploads/2008/03/debunking_specsmanship.pdf [fecha de consulta 5/08/2010].

Wueller, D. (2002): Measuring Scanner Dynamic Range. PICS 2002: Image Processing, Image Quality, Image Capture Systems Conference. Portland, Oregon, April 2002, 163-166.

Wueller, D. (2006): Image Engineering digital camera tests (White Paper) [en línea]. Disponible en: https://noppa.tkk.fi/noppa/kurssi/as-75.2122/luennot/AS-75_2122_kameramittaukset.0.pdf [fecha de consulta 5/08/2010].

Wueller, D.; Dormolen, H. Van, y Jansen, V. (2009): Universal Test Target Technical Specification [en línea]. Disponible en: http://www.universaltesttarget.com/download/ UTT\%20technical\%20specs.pdf [fecha de consulta 25/08/2010]. 